\title{
A sustainable approach to geomatic methods in ravine monitoring and associated natural disaster prevention
}

\author{
Sanda Marioara Naș ${ }^{1}$, Oana Manuela Ciurean ${ }^{2}$, Mircea Vasile Bondrea ${ }^{1}$, Virgil Mihai \\ Rădulescu ${ }^{1}$ \\ 1 Technical University of Cluj Napoca; sanda.nas@mtc.utcluj.ro \\ 2 Melny Topo Cluj-Napoca; manu.ciurean@gmail.com \\ * Correspondence: mihai.radulescu@mtc.utcluj.ro;
}

\begin{abstract}
This paper presents the monitoring of an extremely eroding phenomenon (ravine) near Ciurila, Cluj County, Romania, using UAV (Unmanned Aerial Vehicle) and GNSS (Global Navigation Satellite System) technologies, taking into account the objectives of SDG 15 of the UN resolution, which refers to life on earth. In this sense, the results of a monitoring through sustainable and non-invasive technologies are presented, following three cycles of observations, carried out between June 2019 and April 2021.The paper aims to present the advantages and limitations of such a study, as well as the importance of monitoring erosion phenomena (in this case, ravines) for the ecosystem, but also for the nearby inhabitants. Software and technologies are used that allow the automatic calculation of the volume of the ravine and the displacements between the different measurement cycles, which allows obtaining objective conclusions and proposing further measures.
\end{abstract}

Keywords: erosion; modeling; UAV

\section{Introduction}

The purpose of this article is to bring to attention the importance of monitoring landforms created in the aftermath of the erosion process and the risk that it presents to the nearby community, as well as the effect it has on agriculture in the area. The landform that this study focuses on is a ravine, the largest landform created by erosion. The deep erosion process is due to the water that results from rain or from snow melting. Furthermore, this study will also be looking at the surveying methods and at the data processing and analysis. The UN's SDG 15 deals with life on land, with increased attention to the phenomena of erosion and desertification, so the authors wanted to choose some non-invasive and sustainable methods of surveying the details from the field.

The development of geomatics technologies now allows for the high fidelity assessment of this aspect. These include Global Navigation Satellite System (GNSS) Total Stations + Levels precision, terrestrial and aerial photogrammetry, laser scanners with fixed stations, for each presenting technical data and products analyzed sequentially and corroborated-complementary[1].

It has been decided that the surveying will be done using modern technologies, such as Global Navigation Satellite System (GNSS) receivers and Unmanned Aerial Vehicles (UAV) - drones.

The erosion caused by water is the cause for many damaging events, such as: loss of organic matter in the soil, degradation of soil structure, compaction of soil, reduced infiltration of water, reduced supply in the underground water, loss of the upper layer of soil, loss of nutritional substances from the soil, the creation of trickles that can lead to 
the apparition of ravines, uprooting plants and reducing soil productivity [2]. "Land degradation here primarily refers to the loss of life-supporting land resources through a mix of processes that include soil erosion, soil compaction, destruction of soil structure, loss of soil organic matter, loss of vegetation cover, desertification, salinization, and acidification" [3]. The quality of the soil suffers the most from erosion, with repercussions affecting the fauna and flora and, in the end, affecting the quality of human life. To better understand the term soil quality and the implications it has in this research, the term must be firstly defined: "The notion of "soil quality" (often known as "soil health") is the ability of soil to work as a "living system", since it plays an active role in shaping the interaction between the biotic component (such as animals and plants) and the abiotic component (e.g., light, rocks, water, and air) of ecosystems. Soil quality is intended as "the capacity of a soil to function, within land use and ecosystem boundaries, to sustain biological productivity, maintain environmental quality, and promote plant, animal, and human health". Preserving soil quality is therefore essential to guarantee the balance between human intervention and the resilience of natural systems. Soil conditions not only affect the overall functioning of the ecological infrastructure they belong to, but also food and hydrogeological safety, the protection of biodiversity, the effects of climate change, and trade deriving from ecosystem services" [4]. The study, prevention and amelioration of soil erosion is an issue of sustainable development. Humans have the duty to protect the existing ecosystems, therefore making sure that the flora and fauna are not damaged or destroyed by erosive events, as well as paving the way for future generations, so that they can continue living on our planet. It is already agreed by the research community that "sustainability" must be present in our studies, our policies and our behavior as humans. ". Sustainability is essential for a straightforward reason: the quality of life and the Earth's ecosystems' prosperity cannot be maintained if it is not addressed. Therefore, sustainability is one of the world's fundamental objectives, driving the vision and establishing the policies and treaties for sustainable development worldwide" [5].

The study area is located in Romania, in Cluj County, near the village Ciurila. Cluj County is situated in the north-western part of Romania, in the Hill Depression of Transylvania. Going into further detail, the area of interest is located on the southern side of the Feleacu Hill, in the Hășdate Depression. The studied ravine spreads out over an 1170 square meters area, with the following linear dimensions: the valley floor of approximately $64 \mathrm{~m}$ long, the width ranging from $1 \mathrm{~m}$ at the top to $29 \mathrm{~m}$ at the mouth and the height ranging from $0.2 \mathrm{~m}$ to $12 \mathrm{~m}$, from top to mouth. This study area has been chosen based on the next criteria: the ravine should be active, there should exist accessibility up to the ravine and to muster the necessary conditions for using a GNSS receiver and a drone. The area has been surveyed in a time range of almost two years (from June 2019 to April 2021). The ravine has 3 big parts, as follows: the top of the ravine (where the water trickles concentrate and facilitate the process of dislocation of materials), the guiding channel (the materials are transported through this channel, and where new materials are dislocated from the flanks of the ravine, up to the mouth of the ravine) and the alluvial cone (the place where the materials are deposited).

There are plenty of studies whose purpose is to monitor landslides and try to model their behavior, but there are only a few that do the same for ravines. A landslide and a ravine have a lot of common characteristics and some that tell each other apart. The importance of monitoring such hazards is very well put in many research papers on landslides. "Geological disasters are responsible for the loss of human lives and for significant economic and financial damage every year. Considering that these disasters may occur anywhere-both in remote and/or in highly populated areas-and anytime, continuously monitoring areas known to be more prone to geohazards can help to determine preventive or alert actions to safeguard human life, property and businesses" [6] We will try to conduct a comparison between the two hazards in an attempt to emphasize the importance of monitoring ravines and preventing further land degradation and 
economic losses. One of the key differences between a ravine and a landslide is the trigger causing them. Landslides appear when the soil is replete with water and the weight of the landmass is big enough that it can be moved by gravitational forces. Ravines, on the other hand, are the result of many trickles and streams of water carving the upper layers of the soil, detaching and transporting sediments towards the alluvial cone. The semblance between landslides and ravines comes from the effect they have on the environment and from the complexity of factors contributing to the evolution of these hazards. "There are many factors affecting landslides, such as topography, lithology, hydrology, rainfall, vegetation, and human activity. Such factors are known as causative or conditioning factors that have complex and nonlinear relationships" [7]. The same factors should be considered in the study of ravines.

The preliminary study of the area of interest has given us some insights about its topography and the causes that have led to the apparition and the expansion of the ravine. The ravine has emerged on a ground consisting of clay, sandy clay and sand, dating from the Sarmatian Era. The soil in the area is brown eu-mesobasic and brown luvic. From a geomorphologic point of view, the ravine has appeared on a differential erosional depression with hillocky aspect. It is located north of the Hășdate Valley and the Ciurila Lake Complex. The vegetation is that of a hill and plateau meadow and the climate is continental temperate, with specific local phenomena, such as thermal inversion and the apparition of the föehn from the Apuseni Mountain. [8,9]

\section{Materials and Methods}

Since the object of this study is the monitoring of the erosion phenomenon, we have used recurrent surveys for data acquisition, specific to the land monitoring discipline. Ideally, the surveys would be planned every 3-6 months, but in practice, this has not be possible due to the COVID-19 pandemic and the restrictions that came along. Therefore, there is a one year gap between surveys, but the results have still been surprising nonetheless.

Table 1. The programming of the surveys and drone flights

\begin{tabular}{ccc}
\hline Name and code & Date & Instrument \\
\hline Cycle 0 - C0 & 28.06 .2019 & GNSS Receiver \\
Cycle 1 - C1 & 23.09 .2019 & GNSS Receiver \\
Flight 1 - F1 & 18.10 .2019 & UAV \\
Cycle 2 - C2 & 15.09 .2020 & GNSS Receiver \\
Flight 2 - F2 & 15.09 .2020 & UAV \\
Cycle 3 - C3 & 06.04 .2021 & GNSS Receiver \\
\hline
\end{tabular}

The surveying methods used for data collection are modern topographical methods. These methods present many advantages compared to classical methods, in terms of time, economy, and precision. The methods used for monitoring our ravine are the same that can be used for landslide monitoring, another similarity that can be associated with both landslides and ravines.

Two widely spread methods have been used for the survey: using GNSS for surveying detail points and using photogrammetry for acquiring a larger set of data that complements the detail points. The same methods can be successfully used for mapping landslide hazards: "Field surveys and visual interpretation of aerial photographs are the prevailing methods to map landslides. However, the mentioned approaches are limited because of the accessibility to remote areas for field surveys. Moreover, these approaches depend on the visual interpretation of expert experience and knowledge" [10]

GNSS is used to define all the navigation systems that are based on satellites. Topographers use GNSS receivers to determine the coordinates of one or more points located on Earth's surface with precision, in a given coordinate system. "Since 1990, global 
navigation satellite systems (GNSS) have been frequently used to monitor landslides, enabling researchers to determine landslide kinematics, by measuring displacements of a few centimeters working in differential mode. GNSS surveys are usually carried out with a given frequency (i.e., monthly, weekly) and results are discontinuous over time, and related to the cumulative movements of surface points" [11]. GPS techniques are widely used in Romania for the monitoring of hill stability and landslide hazards, but research shows some limitations to using this technique. "Many traditional monitoring techniques, such as the Global Positioning System (GPS) and leveling techniques, are implemented on potentially unstable hillslopes in order to obtain surface deformation, which can partially decrease economic losses and human casualties. However, limited ground monitoring equipment still hardly meets the demand of landslide warnings, especially in mountainous regions where numerous sudden landslides occur." [12]

Therefore, new methods need to be developed and used, methods that have fewer limitations and better efficacy. Airborne photogrammetry is such a method. Though photogrammetry has existed as a method for the past 150 years, only recently has it begun to be widely used in various fields. "Photogrammetry, as its name implies, is a three-dimensional coordinate measuring technique that uses photographs as the fundamental medium for metrology or measurement. The fundamental principle used in photogrammetry is triangulation. By taking photographs from at least two different locations, so-called 'lines of sight' can be developed from each camera to point on the object. These lines of sight, sometimes called rays owing to their optical nature, are mathematically intersected to produce the three-dimensional coordinates of the points of interest" [9]. The apparition and development of UAVs and numerous cameras and sensors that can be attached to them and the accessible price of such technology, UAV photogrammetry has taken on a very large palette of topographical works, hazard monitoring being one of them. It has been used in plenty of studies on landslides, therefore it is worth using on the monitoring of a ravine. "Airborne photogrammetry has also been frequently used in landslide studies to analyze both individual ground movements and wider regions. In these studies, after block orientation based on conventional techniques of aerial triangulation and block adjustment, digital terrain models (DTMs) or digital surface models (DSMs) are calculated using automatic correlation techniques" [13].

The GNSS receiver used was GeoMax Zenith10, accompanied by the Getac PS236 PDA. The drone used was DJI Mavic 2 Enterprise, a UAV that has a photo-video camera and a built-in GNSS receiver.

The topographical method used for the ground survey was the section method. This method has been chosen after studying the landform in the land exploration phase. Because the ravine has a transversal V-section, we have decided that we could recreate it best using multiple sections in key points. The key points have also been chosen during exploration. They were the points in the valley floor where we identified falls. In order to render the valley floor and its development, we have also surveyed points in the valley floor and later created its longitudinal section. The points chosen for both the transversal and the longitudinal sections are slope-changing points.

For processing the data obtained, multiple software has been used, such as : AutoCAD, TopoLT, Agisoft Photoshape Professional, Global Mapper, Microsoft Excel. Auto$\mathrm{CAD}$ is a computer assisted drawing software created by Autodesk. TopoLT is an extension to AutoCAD created for topographers that helps automatize some of the stages of survey data processing. AutoCAD and TopoLT have been used for processing the data collected by the GNSS receiver: inserting the points at the right coordinates in the national coordinate system (STEREO70), creating the 3D surface and the contour lines, creating the outline of the ravine and drawing the sections. 


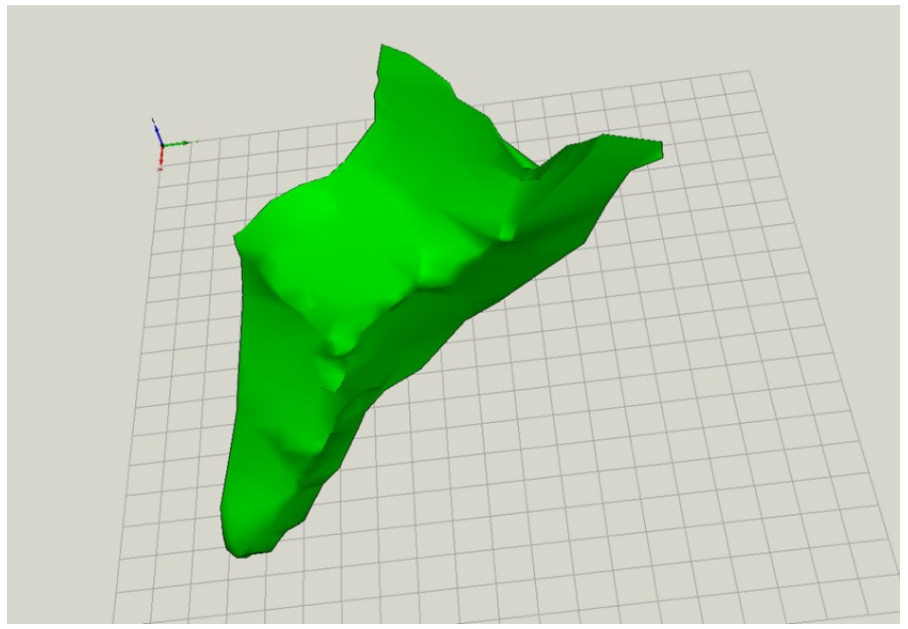

Figure 1. 3D Model obtained from GNSS survey

Agisoft Photoshape Professional is the software that we used to process the images collected by the UAV, to create products that have been used in data analysis: the point cloud, the orthomosaic, the Digital Elevation Model (DEM) and to export them in other formats. Global Mapper has also been used for data analysis based on the orthomosaic and the DEM obtained in Agisoft Photoshape Professional. We have created a watershed map to strengthen the conclusions derived from the mathematical analysis regarding the most affected by erosion areas of the ravine.

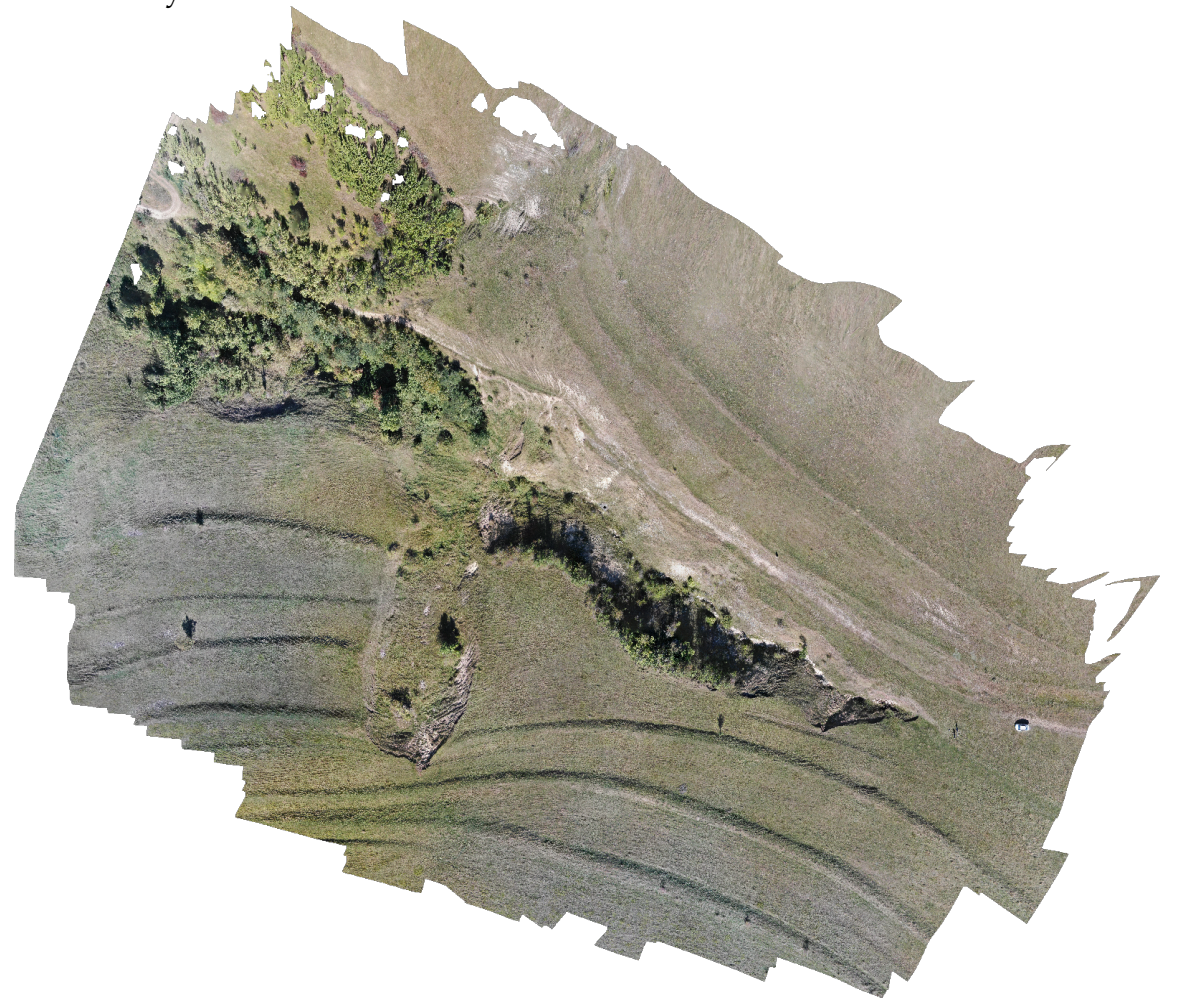

Figure 2. The plan resulted from drone flight above surveyed area

The mathematical analysis has been done using Microsoft Excel, TopoLT and the coordinate files obtained from the GNSS receiver and the drone and its purpose was to identify and quantify the relevant factors in the evolution of a ravine. "Identifying the factors that destabilize the slope and lead to the triggering of a possible event can be 
used to assess and mitigate the hazard. Accordingly, effective policies and strategies may be proposed and implemented to stabilize the displaced material. Numerical modeling of slopes makes use of mathematical equations to solve the mechanical response of the unstable mass." [14]. In order to identify the parts of the ravine where there have been significant clusters or diggings of materials, we have calculated the slopes between our detail points and the average slope for each profile. "The slope is the angle between the plane of the Earth's surface and the horizontal plane. The effects of gravity that determine the water flows and the materials removed vary depending on the slope (on higher slopes, the gravity and the speed of materials are more significant). This combination causes erosion, water and material transportation, and the induction of stress on the slopes, thus increasing the likelihood of landslides" [15].

The formulas used for calculation are the following:

Where:

$$
\begin{aligned}
& p \%=\Delta H / D=100 \\
& p_{m}=\Sigma D \cdot p \% / \Sigma D
\end{aligned}
$$

- $\mathrm{p} \%$ - slope, in percentage

- $\Delta \mathrm{H}$ - height difference between two consecutive points in the profile

- D - distance between two consecutive points in the profile

- $\mathrm{p}_{\mathrm{m}}$ - average slope

\section{Results}

Using both the results from the mathematical calculations and the graphical results obtained from TopoLT and Agisoft Photoshape Professional, we have done the following analyses: volume analyses, the correlation of volumes of materials and the quantity of precipitation and the correlation of the watershed with the most active areas of the ravine. The meteorological data used in this article has been downloaded from www.meteoblue.com. The data acquired from MeteoBlue is based on simulations and not on measurements, because measured data could not be obtained for the desired time period.

\subsection{Analysis of measured volumes}

We have started this analysis by considering the volumes a linear function of time. We have analyzed the values obtained from consecutive cycles and the period of time between the two cycles considered and compared them to the values obtained from comparing the first and the last cycles.
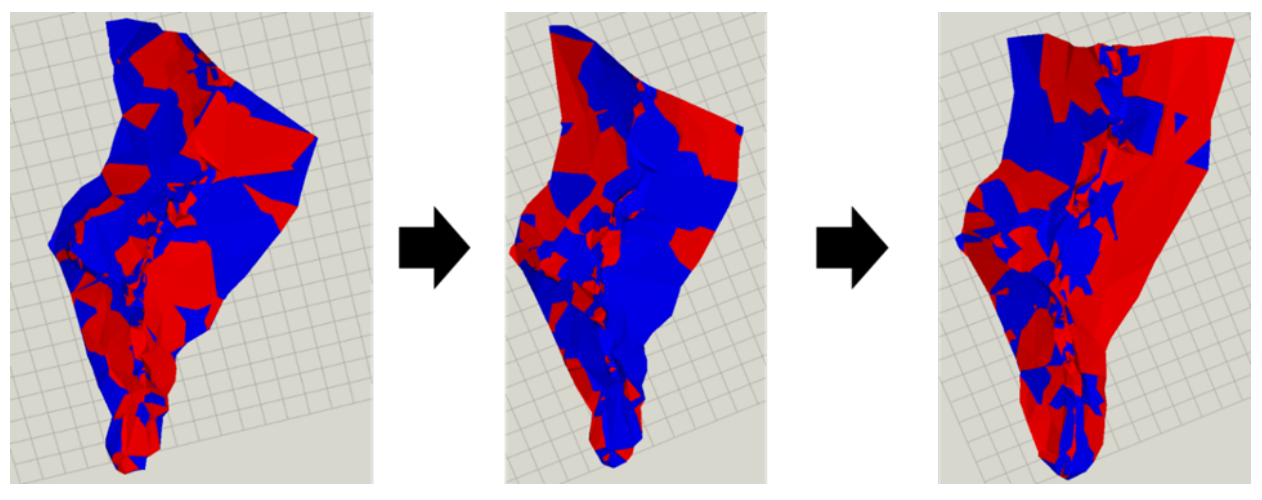

Figure 3. Volume comparisons between consecutive survey cycles: left - comparison between C0 and C1; middle: comparison between $\mathrm{C} 1$ and C2; right - comparison between C2 and C3 (red signifies clusters of materials and blue signifies diggings of materials) 


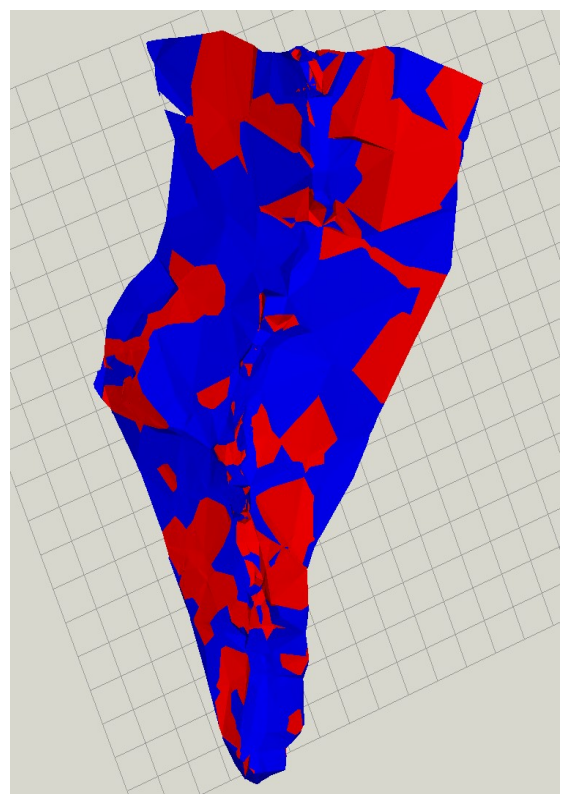

Figure 4. Volume comparisons between $\mathrm{C} 0$ and $\mathrm{C} 3$

Between $\mathrm{C} 0$ and $\mathrm{C} 1$ we can identify the following regions where significant clusters are located: the top of the ravine and the middle of the right flank. On the opposite flank, an area of digging has been identified. Between $\mathrm{C} 1$ and $\mathrm{C} 2$, the most significant clusters are identified on the left flank, while the right flank is characterized by general digging. This changes between $\mathrm{C} 2$ and C3, where the right flank is characterized by clusters, while on the left flank, the areas of clusters and digging are opposed to the previous comparison, showing exactly how and where the materials have moved.

The guiding channel suffers the most radical changes between cycles, as it is continually modeled by the trickles of water and the materials transported. The valley floor is characterized by holes and falls, succeeded by clusters of materials. This changes can be best assessed by comparing the longitudinal profiles.

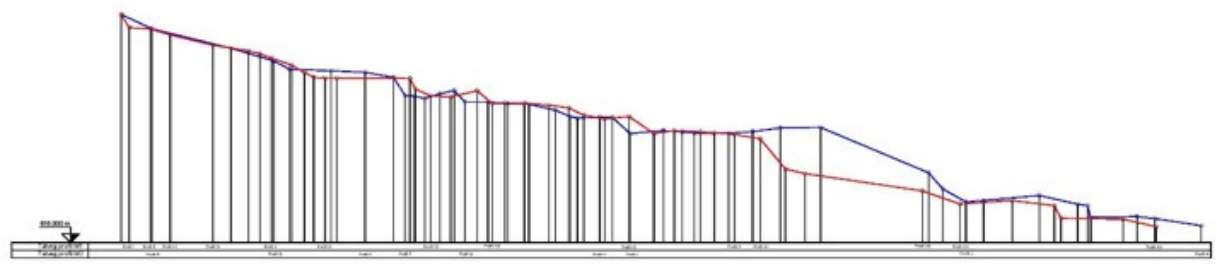

Figure 5. Comparison between the valley floor obtained from C0 (red) and C1 (blue)

The results shown in Figure 4 are based on the heights of points surveyed in $\mathrm{C} 0$ and C3, but after analyzing the results, they should also reflect the summing of height differences and volumes from all the surveying cycles. However, we have identified differences between the volumes obtained by summing the volumes obtained from every cycle and the volumes obtained from C0 and C3.

We have calculated the volume that should have accumulated or been dug and compared it to the value obtained from the $\mathrm{C} 0-\mathrm{C} 3$ comparison. 
The mean has been calculated with the formula:

$$
V_{\text {calculated }}=\frac{V_{C 1} \cdot \Delta t_{1}+V_{C 2} \cdot \Delta t_{2}+V_{C 3} \cdot \Delta t_{3}}{\Delta t_{1}+\Delta t_{2}+\Delta t_{3}}
$$

The difference between volumes has been determined as:

$$
\Delta V=V_{\text {calculated }}-V_{\text {measured }}
$$

The results are presented in the following table:

Table 2. Volume comparisons

\begin{tabular}{cccc}
\hline Comparison between & Cluster $\left(\mathbf{m}^{3}\right)$ & Digging $\left(\mathbf{m}^{3}\right)$ & $\begin{array}{c}\text { Number of months be- } \\
\text { tween surveys }\end{array}$ \\
\hline C0-C1 & 99.82 & -74.58 & 3 \\
C1-C2 & 61.63 & -139.46 & 12 \\
C2-C3 & 91.23 & -53.11 & 6 \\
Calculated volume & 75.54 & -105.52 & \\
C0-C3 (Measured volume) & 54.42 & -78.16 & \\
Difference & -21.12 & 27.36 & \\
\hline
\end{tabular}

The differences between the calculated and the measure volumes could be explained by a multitude of factors and we have considered the most suggestive of them depending on the type of volume. For the clusters, the negative difference is mostly owed to us not knowing the exact quantity of materials going from the ravine to be deposited in the alluvial cone. That value cannot be precisely evaluated in this case because the alluvial cone serves two ravines. In the case of diggings, the positive difference comes from the materials originating from outside of the ravine that are accumulated at a faster rate than the rate with which they can be dug.

\subsection{The watershed analysis}

Using the plans obtained from the drone flights, we have generated the watershed of the studied area.

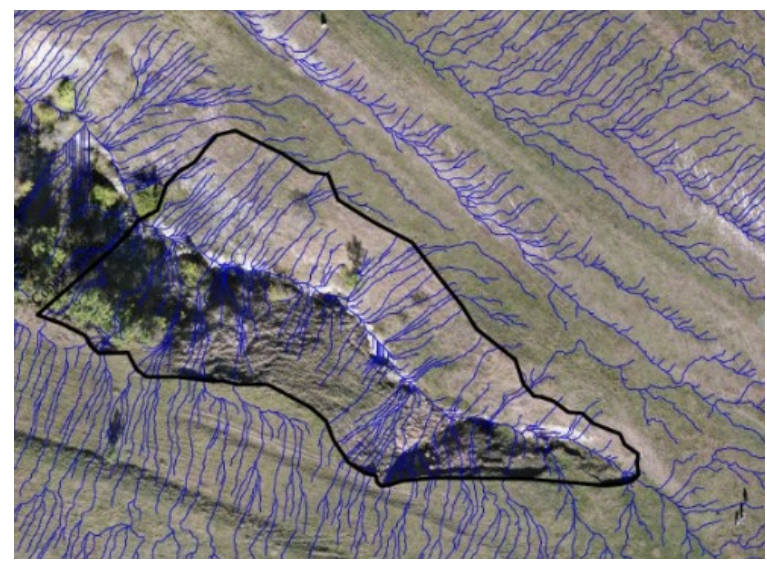

Figure 6. The watershed map 
The areas where the water trickles are denser are the areas where the ravine is most active, meaning that in those areas the clusters and the diggings will be more prominent compared to other areas of the ravine. As can be observed, there are few trickles converging at the top of the ravine, but on the left flank their density increases. Up to the middle of the left flank, these trickles reach a maximum of density in an area that has already suffered major erosion (the ravine has a $v$ shape, but goes outside of the $\mathrm{V}$-shape in this massively eroded area). Furthermore, trickles are dense closer to the mouth of the ravine, due to the very big slopes of the flanks in these areas (slopes of $80-85^{\circ}$ ). These areas can also be identified as the areas that change the most between cycle comparisons.

\subsection{The correlation between volumes of materials and the quantity of precipitation}

We have looked further into the matter and tried to correlate the measured volumes with the quantity of precipitation. We have considered precipitation as the most prominent factor in the expansion of the ravine. The importance of rainfall in geological hazards has been previously emphasized in other research papers: "Rainfall usually increases the pressure heads in the slope and leads to a groundwater flow pattern change and a groundwater table rise" [15]. Therefore, we considered the quantity of materials dislocated a direct result of the quantity of precipitation in a period of time. Based on the measured volumes and the monthly quantity of precipitation, we have determined a mean value of materials clustered or dug for every $1 / \mathrm{m}^{2}$ of precipitation. The results of this analysis are presented in the following:

Table 3. Volume and precipitation correlation

\begin{tabular}{|c|c|c|c|}
\hline & $\mathrm{C} 0-\mathrm{C} 1$ & $\mathrm{C} 1-\mathrm{C} 2$ & $\mathrm{C} 2-\mathrm{C} 3$ \\
\hline Cluster volume $\left(\mathrm{m}^{3}\right)$ & 99.82 & 61.63 & 91.23 \\
\hline Dug volume $\left(\mathrm{m}^{3}\right)$ & -74.58 & -139.46 & -53.11 \\
\hline Time interval $\Delta \mathrm{t}$ (months) & 3 & 12 & 6 \\
\hline $\begin{array}{l}\text { Quantity of precipitation for period } \\
\text { of time } \Delta t\left(1 / \mathrm{m}^{2}\right)\end{array}$ & 49.40 & 526.80 & 242.25 \\
\hline $\begin{array}{l}\text { Mean quantity of precipitation per } \\
\text { month }\left(1 / \mathrm{m}^{2}\right)\end{array}$ & 16.47 & 43.90 & 40.38 \\
\hline $\begin{array}{l}\text { Monthly cluster volume for mean } \\
\text { quantity of precipitation }\left(\mathrm{m}^{3}\right)\end{array}$ & 6.06 & 1.40 & 2.26 \\
\hline $\begin{array}{l}\text { Monthly digging volume for mean } \\
\text { quantity of precipitation }\left(\mathrm{m}^{3}\right)\end{array}$ & -4.53 & -3.18 & -1.32 \\
\hline
\end{tabular}

Graph 1. Volume and precipitation correlation 


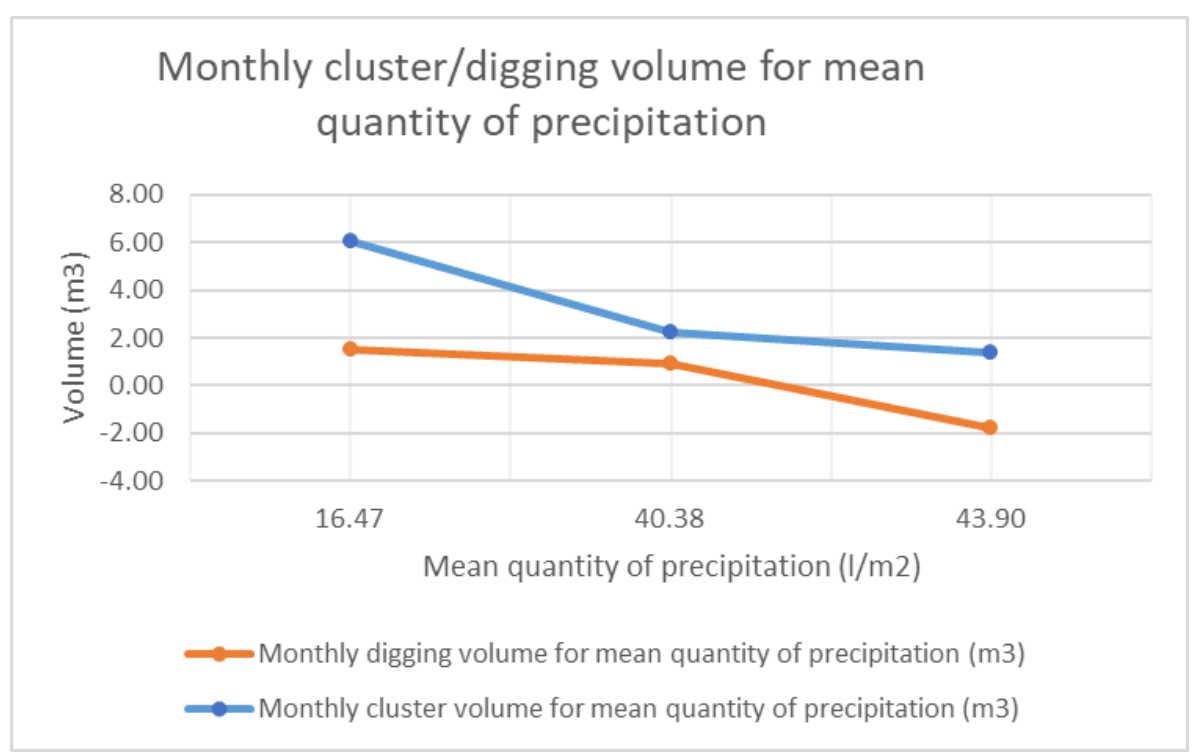

The hypothesis on which we have started working was that there was a proportionality relation between the quantity of precipitation and the volumes (e.g. the bigger the quantity of precipitation, the bigger the digging and the smaller the cluster). However, this hypothesis has been proven wrong by the calculus and has left us to discuss the reasons behind this result and the impact the other factors have on the evolution of the ravine.

\section{Discussion}

As the calculations have shown, modeling the ravine based on only two major factors does not lead to satisfying results. More factors must be integrated in the calculation process in order to refine the results. What these factors are must be determined and the proportion in which they influence the erosion process must be assessed beforehand. International research papers on landslides and hill stability monitoring can show us new methods that we can try to integrate in the study of the erosion process. Different methods have been used in other research papers, as follows: "Owing to the complex nature and inconsistent mechanism of landslides, understanding the major triggering factors underlying their occurrences and modeling their spatial probability have been challenging tasks, mainly researched through statistical, deterministic, and heuristic approaches" [16]. "The statistical methods are usually constructed using linear correction analysis between historical landslides and predisposing factors. On the other hand, deterministic methods require the estimations of quantitative measures of stability factors across given a region and several necessary parameters (e.g., soil strength and layer thickness). In heuristic approaches, expert opinions are employed for predicting landslide hazards by using predisposing factors, substantially involving the expert knowledge system and analytical hierarchy process. A given hazard is rated considering the professional judgment of the analyst conducting the investigation" [17].

Using different data acquisition methods can also improve the results of our study, in order to reduce the time spent in the field, without reducing the quality of the data. For example, remote sensing techniques have been successfully used in studies of landslides and could be applied to our study of the ravine: "Traditional methods of landslide detection are commonly based on field surveys, in situ measurements, and visual analysis produced by an expert. Pedestrian tracking of potential collapse sites located in areas with difficult terrain is hazardous and time-consuming and does not provide a complete picture of the condition of the slope. To a certain degree, the results obtained are highly 
influenced by the knowledge and qualification of an expert. The adoption of remote sensing techniques for landslide detection has great advantages compared to field surveys. At the regional level, to solve problems associated with mudflow hazards, Earth Remote Sensing (ERS) data from satellites (multispectral and radar) are often used, the advantage of which is accessible to any territory, and the absence of the need for terrestrial field research" [18]

There are also different analyses that we can perform and compare to our results. For example, we could use "modern techniques encompassed morphometrical analysis of DEMs and interpretation of aerial photographs, orthoimages and hillshade models in a GIS environment, along with analysis of terrain 3D models to extract virtual measurements and better observe the morphological features" [19].

A ravine is not an independent landform and cannot be studied without the relations it establishes with the neighboring landforms. That is why the behavior of the ravine cannot be precisely modeled, either mathematically, or graphically. The water trickles originate from outside of the ravine and only converge in the ravine, bringing along with them alluvial deposits from their course. That is how materials that are not original to the ravine's body end up being transported in the ravine. The quantity of these materials cannot be precisely evaluated.

The quantity of precipitation alone cannot be correlated precisely with the dislocated and accumulated volumes. For example, knowing at what point the ground is saturated with water would prove very useful for further analysis. There are other unquantifiable factors related to precipitation that we consider factor in the behavior of the ravine, such as the intensity and direction of precipitation. Other meteorological factors that are hard to quantify are the effect snow has on the terrain (the number of days in which there is snow, its mass or how much of the snow infiltrates the ground and saturates it) and the freeze-unfreeze phenomenon, which results in rock disaggregation. Another possible factor can be the type of weather preceding the rains, as has been observed in a study in Northern Italy: "The erosive events characterized by low cumulated rainfall were always preceded by dry periods (at least a week). In such conditions, we observed that even a limited rainfall amount triggered soil erosion, probably due to the extremely low soil moisture that made it more vulnerable to detachment and transport" [20].

\section{Conclusions}

A ravine is a fast-changing landform, suffering drastic changes in short periods of time. This destructive character of the form can prove to be a danger, both for the agriculture in the neighboring area and for the village located a few hundred meters from the ravine. A geological study of the area of interest can be recommended to increase the precision of this study, but also for identifying solutions to ameliorate the affected land.

Speaking from a topographic point of view, the methods used are modern for our country, but there are better methods used worldwide. However, using GNSS and UAV photogrammetry saved us time and money. The field measurements have taken up a small amount of time (a few hours for the GPS and approximately 30 minutes for the UAV), compared to the time we would've spent if we had to use a total station. The number of operators has also been reduced, from minimum 2 for the total station to one for both GPS and UAV. The post processing time has, too, been reduced, as we already had the coordinates from the GPS and UAV, whereas with a total station we would've had to calculate the coordinates before introducing them in the analysis. Another reason 
why using a total station would've been close to impossible is because of the steep slopes and the low stability of the terrain.

In conclusion, traditional topographical methods have plenty of limitations in the study of deep erosion. We have used the most modern methods available to us and the results have been satisfying for the amount of data that we had available. However, there exist better methods that can be used and further analyses that can improve the quality of this study. Moreover, the monitoring of a ravine is a long-time endeavor and can be done continuously, combining the already used methods with the newer ones, giving us insights into the precision of these methods.

Author Contributions: All authors have contributed equally to the work.

Funding: This research benefited from funding from the TUCN Development Program

Data Availability Statement: The data presented in this study are available on request from the corresponding author.

Conflicts of Interest: The authors declare no conflict of interest.

\section{References}

1. Radulescu , V.M. ; Radulescu , G.M.T. ; Nas , S. ; Radulescu , A.T. ; Bondrea , M.V. ; Radulescu , C.M. , Synthetic Analysis Of Geoinformatics Technologies For Preservation Of Cultural Heritage, Methodological Approach, JOURNAL OF APPLIED ENGINEERING SCIENCES 2021 , DOI : 10.2478/jaes-2021-0005

2. https://esdac.jrc.ec.europa.eu/projects/SOCO/FactSheets/RO\%20Fact\%20Sheet.pdf, (accessed on October 27th , 2021)

3. Ewunetu, A.; Simane, B.; Teferi, E.; Zaitchik, B.F. Mapping and Quantifying Comprehensive Land Degradation Status Using Spatial Multicriteria Evaluation Technique in the Headwaters Area of Upper Blue Nile River. Sustainability 2021, $13,2244$. https://doi.org/10.3390/su13042244

4. Nickayin, S.S.; Perrone, F.; Ermini, B.; Quaranta, G.; Salvia, R.; Gambella, F.; Egidi, G. Soil Quality and Peri-Urban Expansion of Cities: A Mediterranean Experience (Athens, Greece). Sustainability 2021, 13, 2042. https://doi.org/10.3390/su13042042

5. Szabo, Z.K.; Szádoczki, Z.; Bozóki, S.; Stănciulescu, G.C.; Szabo, D. An Analytic Hierarchy Process Approach for Prioritisation of Strategic Objectives of Sustainable Development. Sustainability 2021, 13, 2254. https://doi.org/10.3390/su13042254

6. Sousa, J.J.; Liu, G.; Fan, J.; Perski, Z.; Steger, S.; Bai, S.; Wei, L.; Salvi, S.; Wang, Q.; Tu, J.; Tong, L.; Mayrhofer, P.; Sonnenschein, R.; Liu, S.; Mao, Y.; Tolomei, C.; Bignami, C.; Atzori, S.; Pezzo, G.; Wu, L.; Yan, S.; Peres, E. Geohazards Monitoring and Assessment Using Multi-Source Earth Observation Techniques. Remote Sens. 2021, 13, 4269. https://doi.org/10.3390/rs13214269

7. Pradhan, B.; Sameen, M.I.; Al-Najjar, H.A.H.; Sheng, D.; Alamri, A.M.; Park, H.-J. A Meta-Learning Approach of Optimisation for Spatial Prediction of Landslides. Remote Sens. 2021, 13, 4521. https://doi.org/10.3390/rs13224521

8. Multiple aut., Geografia României I. Geografia fizică, Editura Academiei Republicii Socialiste România, București, 1983,113114

9. Multiple aut., Geografia României III. Carpații Românești și Depresiunea Transilvaniei, Editura Academiei Republicii Socialiste România, București, 1987, 57-58

10. Shahabi, H.; Rahimzad, M.; Tavakkoli Piralilou, S.; Ghorbanzadeh, O.; Homayouni, S.; Blaschke, T.; Lim, S.; Ghamisi, P. Unsupervised Deep Learning for Landslide Detection from Multispectral Sentinel-2 Imagery. Remote Sens. 2021, 13 , 4698. https://doi.org/10.3390/rs13224698

11. Zárate, B.A.; El Hamdouni, R.; Fernández, T. GNSS and RPAS Integration Techniques for Studying Landslide Dynamics: Application to the Areas of Victoria and Colinas Lojanas, (Loja, Ecuador). Remote Sens. 2021, $13,3496$. https://doi.org/10.3390/rs13173496

12. Yang, D.; Qiu, H.; Zhu, Y.; Liu, Z.; Pei, Y.; Ma, S.; Du, C.; Sun, H.; Liu, Y.; Cao, M. Landslide Characteristics and Evolution: What We Can Learn from Three Adjacent Landslides. Remote Sens. 2021, 13, 4579. https://doi.org/10.3390/rs13224579

13. Josh Horswell, Encyclopedia of Forensic Sciences, Pages 368-371, Academic Press, 2013

14. Necula, N.; Niculiță, M.; Fiaschi, S.; Genevois, R.; Riccardi, P.; Floris, M. Assessing Urban Landslide Dynamics through MultiTemporal InSAR Techniques and Slope Numerical Modeling. Remote Sens. 2021, 13, 3862. https://doi.org/10.3390/rs13193862

15. Ramos-Bernal, R.N.; Vázquez-Jiménez, R.; Cantú-Ramírez, C.A.; Alarcón-Paredes, A.; Alonso-Silverio, G.A.; G. Bruzón, A.; Arrogante-Funes, F.; Martín-González, F.; Novillo, C.J.; Arrogante-Funes, P. Evaluation of Conditioning Factors of Slope In- 
stability and Continuous Change Maps in the Generation of Landslide Inventory Maps Using Machine Learning (ML) Algorithms. Remote Sens. 2021, 13, 4515. https://doi.org/10.3390/rs13224515

16. Dai, X.; Schneider-Muntau, B.; Fellin, W.; Franco, A.; Gems, B. Engineering-Geological Analysis of a Subaerial Landslide in Taan Fiord, Alaska. Remote Sens. 2021, 13, 4258. https://doi.org/10.3390/rs13214258

17. Kavzoglu, T.; Teke, A.; Yilmaz, E.O. Shared Blocks-Based Ensemble Deep Learning for Shallow Landslide Susceptibility Mapping. Remote Sens. 2021, 13, 4776. https://doi.org/10.3390/rs13234776

18. Gantimurova, S.; Parshin, A.; Erofeev, V. GIS-Based Landslide Susceptibility Mapping of the Circum-Baikal Railway in Russia Using UAV Data. Remote Sens. 2021, 13, 3629. https://doi.org/10.3390/rs13183629

19. Gaidi, S.; Galve, J.P.; Melki, F.; Ruano, P.; Reyes-Carmona, C.; Marzougui, W.; Devoto, S.; Pérez-Peña, J.V.; Azañón, J.M.; Chouaieb, H.; Zargouni, F.; Booth-Rea, G. Analysis of the Geological Controls and Kinematics of the Chgega Landslide (Mateur, Tunisia) Exploiting Photogrammetry and InSAR Technologies. Remote Sens. 2021, 13, 4048. https://doi.org/10.3390/rs13204048

20. Stanchi, S.; Zecca, O.; Hudek, C.; Pintaldi, E.; Viglietti, D.; D’Amico, M.E.; Colombo, N.; Goslino, D.; Letey, M.; Freppaz, M. Effect of Soil Management on Erosion in Mountain Vineyards (N-W Italy). Sustainability 2021, 13, 1991. https://doi.org/10.3390/su13041991 